\title{
Cycling intellectualization in Smart Cities
}

\author{
I.V. Makarova, K.A. Shubenkova* and A.D. Boyko \\ Kazan Federal University, pr-t Syuyumbike, 10a, Naberezhnye Chelny, Russia
}

\begin{abstract}
Intellectualization is the basis for managing Smart Cities. This involves infrastructure development and design of vehicles equipped with intelligent modules, which provide the control ability. Along with it, the transition to "green", safe and sustainable modes of transport, such as bicycle, should be realized. The widespread use of environmentally friendly bicycles is constrained by a number of reasons. The first is the absence of models designed for physically untrained people and the second is that almost half of all deaths on the world's roads are among pedestrians and cyclists. We propose to solve these problems in two ways: development of an information system for bicycle infrastructure planning and modelling and creating control system of Smart Bike with adaptive electric drive that turns on when it's necessary. Functional requirements for the proposed control system, its algorithm and the conceptual scheme of interaction between system's modules are presented in the article.
\end{abstract}

Keywords: Smart City, intellectualization, control system, Smart Bike, sensors, controllers, Internet of Things, transport system

Received on 12 August 2017; accepted on 12 November 2017; published on 20 December 2017

Copyright (C) Makarova et al., licensed to EAI. This is an open access article distributed under the terms of the Creative Commons Attribution licence (http://creativecommons.org/licenses/by/3.0/), which permits unlimited use, distribution and reproduction in any medium so long as the original work is properly cited.

doi: 10.4108/eai.20-12-2017.153498

\section{Introduction}

Despite the increasing level of urban mobility worldwide, access to places, activities and services has become increasingly difficult. Owing to urban sprawl - the horizontal, low-density growth of cities over vast areas - distances between functional destinations such as workplaces, schools, hospitals, administration offices, or shopping amenities have become longer, leading to a growing dependency on private motorized transport and other car-centered mobility. Consequently, widespread congestion and traffic gridlock have now become the norm in many cities, impacting urban life through negative externalities such as pollution, noise stress, and accidents. Thereby, the government has now realized the need for cities that can cope with the challenges of urban living and also be magnets for investment.

This can be developed through environmental sustainable solutions combined with a full use of the possibilities, which are given by the digitalization of the society. This means enabling the technology to gather data, which can be used by the technology itself in order to adapt to the most sustainable and smart behaviour. Enabling the technology to communicate, to share the gathered data with people or other technologies, to borrow relevant data from elsewhere and to make the technology multifunctional - all of this provides solutions not only to one, but to multiple problems [1].

The Smart City concept can be defined as a model of the city development, which creates a surplus of resources through the use of information and communication technologies combined with sustainable and environmentally friendly multiple solutions. It emphasizes the need to improve the level of mobility and connectedness through collaboration and open source knowledge on all levels of the society [2].

One of the main ways to create a Smart City is Smart Transportation systems' implementation, which is in line with the United Nations Sustainable Development Goals and the Transition to a Green Economy. As far as transport starts to be one of the main sources to produce air pollution, emissions of greenhouse gases, noise as well as one of the main reasons of the consumption of nonrestorable resources, household inconveniences caused, for example, by the neighborhood with a highway, etc. [3], the number of adherents of transition to a green economy is growing. They

*Corresponding author. Email:ksenia.shubenkova@gmail.com 
initiate the development of strategies and policy documents on sustainable development of the urban transportation systems.

Transition to a Smart Transport involves the development of appropriate infrastructure, which will ensure the rational management of transportation system, as well as the intellectualization of vehicles, which can provide a sustainable urban mobility.

\section{Ensuring sustainable mobility in Smart Cities}

\subsection{Main ways to increase sustainability of the city transport system}

There are three main ways cities can innovate to make transport more sustainable without increasing journey times:

- Better land use planning.

- - Making existing transport modes more efficient.

- Moving towards sustainable transport.

Part of measures to ensure the sustainability of transport can be planning for urban and suburban centres in accordance with development, providing for a mixed fleet of vehicles and reasonable growth. Such principles of urban development will help to reduce dependence on private vehicles and to ensure widespread use of public and non-motorized transport for short trips and for regular commuting into the city from the suburbs [4].

The UNEP report [5] states that in order to achieve economic goals and objectives of sustainable transport development and integrated planning of its development and regulation system load, you need to switch to fuels with lower carbon content and to implement a more extensive electrification of transport.

Safe public transport systems are increasingly viewed as an important tool for safe increase of mobility of the population, especially in urban areas suffering from growing traffic congestion. In many cities with high income the policy of reducing the use of personal motor transport is particularly emphasized through investment in the development of public transport networks. [6].

According to the Global Status Report on Road Safety 2015 [3], moving towards more sustainable modes of transport (such as cycling and public transport) has positive effects if associated road safety impacts have been well managed. These include increased physical activity, reduced emissions and noise levels, reduced congestion and more pleasant cities.

Moreover, measures to promote safe public transport and non-motorized means of transport are also in line with other global moves to fight obesity and reduce noncommunicable diseases (such as heart disease, diabetes) [7].

\subsection{Benefits of using bicycles as a travel mode and examples of their implementation}

International experience shows that countries have a choice when it comes to the development of the pattern of motorization. Rather than opting for a pattern of high use of private vehicles (as the one in the United States or Australia), cities have the possibility of a more balanced approach (as in Europe) or select what was labeled by UITP as the most efficient pattern (Tokyo, Amsterdam, Hong Kong, Madrid). This pattern has the smallest role for private motorized vehicles in meeting demand for transport and the highest share of public transport, walking and biking [8].

Considering the fact, that the world community has set an objective to reduce the levels of greenhouse gases (first of all carbon dioxide) by $50 \%$ by 2050 [4], bicycles get an additional advantage, as they do not produce $\mathrm{CO}_{2}$ emissions. Furthermore, bicycling makes efficient use of roadway capacity and reduces congestion. The advantages of cycling include cheap infrastructure requirements and improvements in public health. Bicycle pathways, lanes and parking require less space than their automobile counterparts. Cycling has direct health benefits. It is an aerobic exercise that can minimize the risk of muscle and ligament injury, lower blood pressure and reduce the risk of heart disease) [9]. Moreover, in urban areas, cycling can sometimes prove to be faster than other transport modes and also allows cyclists to avoid traffic jams.

Cycling caters for the mobility needs of considerable numbers of urban dwellers in developing country cities, especially in Asia. Problem of the environmental pollution is a major issue in China with its notoriously poor air quality in large cities. Probably, this was the main reason of China's bicycle development [10]. In 2014 Lanzhou (Northwest China) was praised for integration Asia's second-largest bus rapid transit system with a bike share system (14,000 docks planned), bike parking, and greenways [11]. Bike share system is also implemented in such cities as Beijing, Zhuzhou, Shanghai, Wuhan and Hangzhou [12], where the popularity of this mode of transport is also provided by the widespread introduction of electric bicycles that help physically untrained people to overcome steep climbs and long distances, that's why an increasing number of people choose non-motorized transport as a travel mode. In India, household bicycle ownership rates are high in cities such as Delhi (38 per cent), Ahmedabad (54 per cent) and Chandigarh (63 per cent). This is reflected in the relatively higher modal share of cycling in these cities Delhi (12 per cent) and Ahmedabad (14 per cent). In some Asian countries with relatively higher incomes, however, the modal share of cycling is much lower, such as in Singapore (1.6 per cent of work trips), 9 the Republic of Korea (1.2 per cent) 10 and Hong Kong SAR (0.5 per cent) [7].

In African cities, cycling plays a comparatively limited role, accounting for less than 3 per cent of total trips in capital cities such as Bamako (Mali), Dakar (Senegal), Harare (Zimbabwe), Nairobi (Kenya) and Niamey (Niger). To promote bicycling in African city of Dar-es-Salaam Nkurunziza et al. in their study [13] identified the bicycling policies. Also, technology can be used not only to make better 
cars but also better cycle paths, such as the proposed airconditioned bike path in Qatar [14].

Such cities of Latin America as Bogotá, Medellín, León, Buenos Aries, Rio de Janeiro, São Paulo, Several Chilean cities, etc. have included to their local and national strategies of transportation system's development such projects as introduction of permanent bike paths and bike lanes, safe parking and transit stations [15]. Rio de Janeiro launched a bike-sharing program, it has now 600 bicycles and $200 \mathrm{~km}$ of bike routes. São Paulo launched the establishment of bicycle lanes more than $120 \mathrm{~km}$ long. After the general street protests that occurred in Brazil in June 2013, triggered by the high cost and low quality of public transport, the Municipality of São Paulo announced a further $310 \mathrm{~km}$ of bike routes, which are actually signaled lanes shared with cars [16].

In car dependent countries such as Australia, Canada and the USA the proportion of non-motorized trips up less than an eighth of daily trips. However, it is shown in [9] that investment in well-designed bicycle facilities (pathways, lanes and roadways) in the largest Canadian cities (for example, Calgary) has resulted in modest shifts in the commuting patterns to work in favor of cycling.

Bicycle ownership in Western Europe, especially in the Netherlands, Germany and Denmark, is very high and if cycling in the US is mostly for recreational and fitness purposes, in Europe it is a key means of movement for utilitarian purposes. Today, in some European cities - such as Amsterdam or Copenhagen - two-thirds of all road users are cyclists. In other words, it is perfectly feasible for a majority in a metropolis to ride a bike and not travel by car. Not everybody can ride a bike every day, however, which is why the bike should not be seen as a competitor, but rather as complementary to public transport. Especially on the way to and from work, there is a lot of potential: in London around 2.5 percent of all commutes to work are by bike, in Berlin 13 percent, in Munich 15 percent and in Copenhagen and Amsterdam a whopping 36 and 37 percent respectively. Such a high percentage of number of trips to work or education by bicycles in Copenhagen is provided by the fact that the priority strategy of politicians is development of bicycles infrastructure as a way to create more friendly city living condition [17]. For example, there are currently several programmes in Europe testing the introduction of cargo bikes, including the EU-funded project CycleLogistics. While the main focus of the project has been on urban freight and courier services, it has also included shop-by-bike campaigns. Indeed, private cargo bike use is a reality in cities like Copenhagen $[14,18]$. The so-called "carbon footprint" of Copenhagen is one of the smallest in the world (it is less than two tonnes per capita). But there is even more ambitious goal to become neutral on emissions has been set in its development strategy. To do this there have been set very strict targets in order to follow energy efficiency standards, "green" construction and "green" energy. The city government approved the project of equipping bicycles with special sensors that report on the level of pollution and traffic congestion in real time [19].

In Portugal as inductor of desired modal shifts (changing behavior from using cars to other modes such as cycling) local administration of the city Lagoa conducted an experiment. Each employee of the city council travelling from home to work (and vice versa) and able to shift their usual mode of transport (car) to other options (walking, cycling with public bicycles, electric bicycles, car sharing) could be offered "money vouchers" (equivalent carbon credits to their reduced $\mathrm{CO}_{2}$ emissions). These vouchers were redeemable in several public facilities and cultural events [20]. There is an effective bike sharing system in London, Barcelona and Paris. To use such a system you need to register and receive a personalized card. In Barcelona, you can rent a bike and leave it at any convenient point of the city, because there are bicycle parkings all over the major streets. An extensive network of bicycle paths and cycling facilities and services are also contributes to the development of this system. Essential infrastructure in a city with the size and traffic volume of Moscow includes a strategy for secure parking lots and allowing for alternative ownership structures through a bike share system. Moscow decided to introduce various parking facilities appropriate for short-term and longterm parking and to introduce a bike sharing system similar to schemes in London, Barcelona and Paris [21].

Thus, in the last decade non-motorized transport has become a symbol of sustainable urban transport all over the world.

\subsection{Factors that prevent bicycle transport usage and the ways to increase its attractiveness}

Cycling is a low-polluting and a low-cost transportation alternative and can be an important mean for getting to destinations that are not serviced by transit [22]. However, a considerable proportion of commuters choose to use other means of transport. Even in the Netherlands, which has a bicycle-friendly infrastructure and where cycling has a positive image, many people choose not to cycle in situations when cycling would be a highly appropriate transport mode.

The impediments to bicycling include factors like long trip distances of commuters, harsh weather conditions, greater physical effort, the difficulty of carrying loads while cycling, infrastructure unavailability, a lack of health and environment consciousness among people, extreme traffic conditions that lead to the risk of an accident [23] and, outside urban areas, travelling more slowly than motorized transport. Factors such as physical effort and speed also limit the distance that a cyclist can travel [24].

One of the most popular counter-argument about cycling are adverse climatic and natural conditions. However, it is a matter of attitude and priority for cycle paths when clearing snow. This is confirmed by the example of Oulu, where a substantial proportion of people commute by bicycle, even when the temperature is below zero in deepest winter. This is ensured by $845 \mathrm{~km}$ of routes (4.3m per inhabitant), $98 \%$ of which are maintained throughout winter because main route maintenance priorised over driveways. Routes parallel to driveways are separated with a green lane, which also serves as snow build-up space. There are underpasses in most busy 
crossings and you can reach every place by bike using cycling routes [25].

Introducing bicycle lanes is not enough to make a city attuned to cyclists' needs. Thus, despite the investments in London's cycling infrastructure of about 4 billion dollars over the last 10 years, the proportion of commuting by bicycle has increased from $1.2 \%$ to $2.5 \%$. A similar situation is observed in the United States, where more than 15 billion dollars over the last 10 years were invested in development of cycling infrastructure and where commuting by bicycle has increased only from $0.3 \%$ to $0.6 \%$ during this period. In New York, despite the 300 miles built safe bicycle lanes (which are separated from vehicles and pedestrians) over the last 10 years, commuting by bicycle has increased from $0.6 \%$ to $1.1 \%$. A radical change in modal split in favor to bicycle transport is often hampered by considerable distances from centers to the points of passengers' attraction in metropolitan areas. The diagram below confirms this conclusion (Fig. 1).

The research of the ways to increase the sustainability of urban transportation system was based on the assumption that population will prefer the cycling as a mode of transport in a case if there is a considerable advantage of its using.

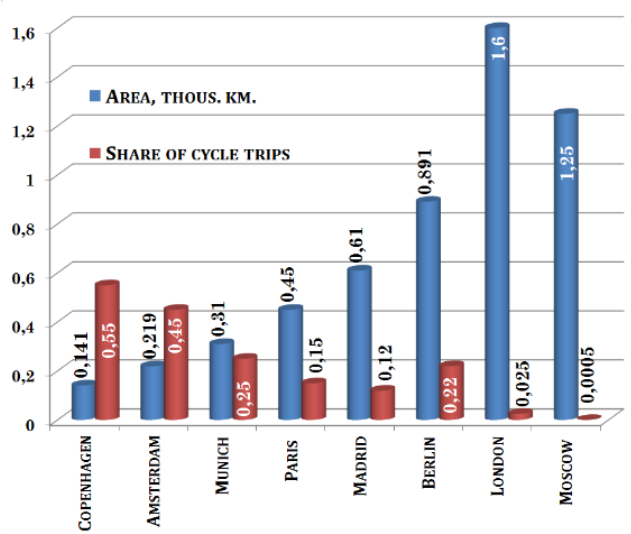

Figure 1. Relation between the number of cycling commutes and the city size
One of the most objective methods to study the transport preferences of the population is a questionnaire survey that allows predicting the most likely options of the transportation system development. Survey was held in Naberezhnye Chelny - one of the most young Russian cities. Linear structure open type with the "classic" functional zoning was laid in the basis of planning organization of the city with a parallel location of industrial and residential areas, suburban recreation zones. In connection with these peculiarities of urban planning, in the case when the destination point is situated on the longitudinal avenue that is parallel to the point of departure) and there is the lack of the lateral routes of public transport in the city, the "last mile" problem exists in Naberezhnye Chelny [26]. The questionnaire to find out what transport modes are the most popular among population has been developed. 953 respondents, constituting the various target groups, took part in the current survey (Table 1) [27]. Results of the research show that one of the deterrent constraints of cycling development are psychological factors. They, in turn, may be due to various reasons: from the incertitude of ability to overcome the route due to the individual physical characteristics, to the lack of information about the route characteristics.

Therefore, the number of people who choose bicycle as a mode of transport can be increased by the expansion of nonmotorized model line-up and the integration of its infrastructure to the city road network system. What is more, cycling facilities and services should be developed. These steps, on the one hand, will help to enhance the attractiveness of bicycles for different groups of population and, on the other hand, will make roads safer and more secure particularly for non-motorized road users who are the most vulnerable.

In simplified form, ways to increase the attractiveness of non-motorized transport are shown on the Fig. 2.

Table 1. The results of the sampling survey of population

\begin{tabular}{|c|c|c|c|c|c|}
\hline Indicator & 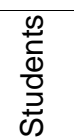 & $\begin{array}{l}\frac{\infty}{\bar{\omega}} \\
\frac{2}{\grave{2}} \\
\vdots\end{array}$ & 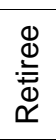 & 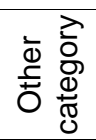 & 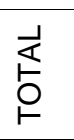 \\
\hline number of respondents & 624 & 299 & 16 & 14 & 953 \\
\hline number of trips to work or education by public transport & 313 & 109 & . & $r$ & 422 \\
\hline number of trips to work or education by bicycles & 50 & 7 & - & & 57 \\
\hline number of trips to work or education by cars & 163 & 133 & - & 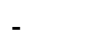 & 296 \\
\hline number of trips to work or education by foot & 98 & 50 & - & - & 148 \\
\hline $\begin{array}{l}\text { number of bikes in the personal property } \\
\text { the number of drivers who are ready to transfer to bicycles, if there are: }\end{array}$ & 313 & 86 & 2 & 6 & 407 \\
\hline bikeways & 127 & 56 & 0 & 0 & 183 \\
\hline bicycles parkings & 129 & 46 & 0 & 0 & 175 \\
\hline bike hire system & 75 & 28 & 0 & 0 & 103 \\
\hline the possibility to take the bike in buses or trams & 76 & 21 & 0 & 0 & 97 \\
\hline E-bikes & 78 & 22 & 0 & 0 & 100 \\
\hline
\end{tabular}




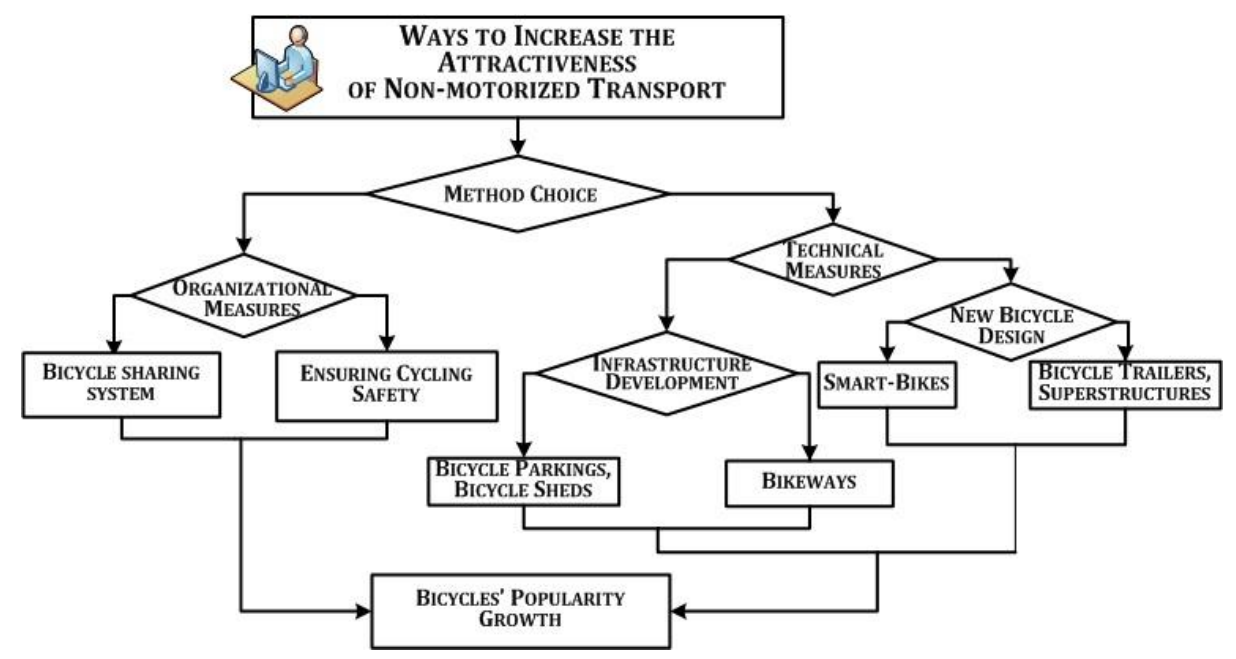

Figure 2. Measures to implement for moving towards non-motorized modes of transport

Thus, as the experience shows, one of the deterrent constraints of cycling development are psychological factors. They, in turn, may be due to various reasons: from the incertitude of ability to overcome the route due to the individual physical characteristics, to the lack of information about the route characteristics.

The case of Copenhagen proved that the attractiveness of cycling may be increased by the expansion of bicycles model line-up for different population groups and different use cases. In Copenhagen you can rent not only conventional bikes, but also such models as [28]:

(i) The Velomobile. It protects against wind, rain and drizzle and it is best suited for long distances over $20 \mathrm{~km}$ and runs well on wide bicycle lanes outside the city and that several users would cycle more in the rain if they had a similar cycle.

(ii) The Cargobike. It is good to transport children and to carry things and products and it is best suited for short distances below 10 $\mathrm{km}$.

(iii) The Recumbent. It is comfortable and good to ride on, especially in headwind and it lends itself well to long distances over 20 $\mathrm{km}$.

(iv) The Electric-assist Long John. It is good to carry cargo and children and it motivates to cycle more and drive less. It is fast, practical, fun and effortless to get around within the city.

(v) The Electric Bicycle. It is fun and different to drive on. The electric slide is a good help, especially uphill and against wind.

Bicycle infrastructure planning should include the creation of bike parkings, bike sheds and bikeways as well as it should be taken into account the terrain and the structure of population, who want to use the bike to get around the city. Despite a fast growing literature on the bike lanes design [29], the problem of terrain identification and topographic conditions modelling is still actual. The most common method of bicycle wayfinding is the shortest path method.

As far as bicycle routing is not always possible to avoid hilly terrain, bike-lifts and electric drives creation can solve the problem of overcoming steep climbs. In contrast to the electric scooter or motorcycle, e-bike may be driven by pedals. At this time electric drive is off and accumulator is charging.

E-bikes are generally different from ordinary bicycle because of three additional components presence such as an electric motor, a storage battery and a battery controller. Despite of electric drive presence electric bike is used approximately the same as an ordinary bicycle and in most countries does not require the driving license or license plate presence. Electric bicycle is suitable as a vehicle for a wide range of people with the different level of abilities, as it is easy to dose physical training. There is a number of disadvantages of electric bicycle that, makes it difficult to use. They are: significant weight (from 20 to $50 \mathrm{~kg}$ or more) and the corresponding inertia; lack of power reserve on the drive (rarely more than $25-50 \mathrm{~km}$ ); long battery charging (usually at least 2-6 hours); short service life of lead-acid and lithium-ion storage batteries; the high cost of the final product and its use compared with an ordinary bicycle cost and use (from 2 to 10 times).

One of the ways to ensure sustainable mobility in Smart Cities is the combination the possibilities of bicycles and electric transport. When using the electric transport, movement parameters are set by the motor and the cyclist determines the trajectory, e.g. performs control. Bicycle movement is provided by the cyclist who sets the driving speed and the movement direction. This means that cyclist manages the process of cycling. But at the same time cycling parameters depend on environmental conditions (including the terrain characteristics), natural conditions, time of day and the physical condition of cyclist. In short, cycling parameters depend on everything that affects the possibility of bicycle movement. If we consider the "bicycle" system, its functioning is provided by the interaction of such subsystems as "external environment" - "infrastructure" - "bicycle" "cyclist". To ensure the traffic safety it is necessary to 
establish a control system that implements the interaction of subsystems for rational functioning of the system.

The most common variant of the bicycle's electric drive is the one that is based on commutatorless DC motor. The engine is build in the wheel instead of the hub. Any of the wheels can be the motor-wheel, as well as the both on them at the same time. Motor-wheel is often sold in assembled form. The power of the motor is determined for the fully loaded electric bicycles, with a maximum speed and without traction of the cyclist. The pattern of the forces acting on the bike when it moves is used for this purpose. Thus, to ensure the maximum speed of movement up to $50 \mathrm{~km} / \mathrm{h}$, for a person weighing $70 \mathrm{~kg}$ the motor wheel of $1000 \mathrm{~W}$ would be enough. To simplify installation, the wheel designed for the bicycle's front fork weighing $6,5 \mathrm{~kg}$ has been selected. This wheel can withstand loads of up to $135 \mathrm{~kg}$.

An example of such bicycle with the DC motor can be the Copenhagen Wheel, that is a rear bicycle that has an in-built electric motor, battery, and in-built computer.

\section{Cycling intellectualization: Our proposed solution}

\subsection{Smart Bike Control System}

\section{Idea of the Smart Bike control realization}

Electric bicycles are controlled by cycling computer (controller), which is supposed to: supply amperage from the battery to the electric motor in accordance with the user's settings; show residual battery charge on the indicator; determine the rotation / stop of pedals; limit the maximum speed of the bicycle movement in order to save energy; keep constant speed (cruise control); charge the battery while braking. At the same time there is a variety of velosimulators that are belong to the group of cardiovascular machines which are equipped to control the physical condition of a user. At the same time the main indicator to diagnose critical state is a pulse rate. As far as the parameters of the bicycle motion are influenced by both condition of the cyclist and the parameters of the environment, the rational management should be based on monitoring, analysis and on taking into account all these factors. Today there are two types of systems that are used to analyse bicycle's characteristics and motion parameters. They are:

- Cycling computers - electronic devices to measure the speed and daily run of bicycle as well as such additional parameters as average speed, travel time, full speed, transmission (for multi-speed bikes), running time, temperature, atmosphere pressure, cadence (pedal rotation frequency), etc.

- Smart phones applications - applications that duplicate functionality of cycling computer, except the ability to monitor the transmission and cadence, use built-in phone sensors such as GPS, accelerometer, barometer.

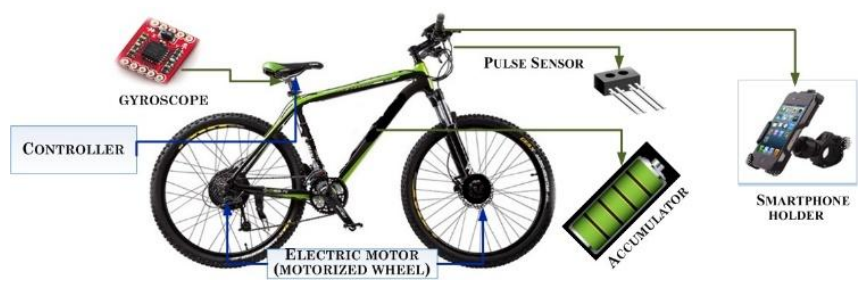

Figure 3. The elements that are included in the developed module

To implement the Smart Bike control idea it is necessary to design a system that combines cycling computer, motorized wheel (it is the type of a driving wheel, complicated mechanism, that combines the wheel itself, electric motor, power gear and braking system) and velosimulator that control the physical condition of a user. Sensors readings are transmitted into the controller for the further analysis. In critical cases (when the physical cyclist's condition is bad) the system sends the request to turn on the electric drive and after receiving the confirmation from user electric drive control is transferred to the controller.

Thus, if to equip the bicycle with the universal module, which includes a pulse sensor, a controller and other components that are shown in Fig. 3, and to manage it in accordance with the selected program installed on smartphone it will help to increase the attractiveness of cycling among untrained population.

\section{Functional requirements for the proposed control system}

Existed sensors and controllers can be used to implement the concept of Smart Bike. To determine the condition of the cyclist and monitoring travel times are required:

- means of identification of a cyclist - to set his physical characteristics in the rest condition;

- $\quad$ pulse sensor - to determine heart rate;

- timer - to determine the travel time, setting training modes.

To measure the parameters of the bicycle will be required:

- gyroscope/accelerometer - to determine the position of the bicycle in the area;

- $\quad$ speedometer - to determine the travel speed;

- $\quad$ sensor of used chain sprockets;

- GPS sensor - for positioning, location and route setting.

Module which determines the weather conditions on the route and transmits it to a smart phone is required to determine the parameters of the environment.

While designing bicycle control system it should be taken into account that the control system is completely autonomous, and the interference from the cyclist is impossible so it may be unsafe for the rider. That's why the principle of feedback between control system and a person should be implemented with the help of notifications. In this 
way, the possibility of accidents in electric drive of bicycle false alarm cases will be excluded.

\section{Smart Bike Control System Algorithm}

Bicycle movement is provided by the cyclist who sets the driving speed and the movement direction. This means that cyclist manages the process of cycling. But at the same time cycling parameters depend on environmental conditions (including the terrain characteristics), natural conditions, time of day and the physical condition of cyclist. In short, cycling parameters depend on everything that affects the possibility of bicycle movement. If we consider the "bicycle" system, its functioning is provided by the interaction of such subsystems as "external environment" - "infrastructure" - "bicycle" "cyclist". To ensure the traffic safety it is necessary to establish a control system that implements the interaction of subsystems for rational functioning of the system.

While designing bicycle control system the list of monitored events and the system's responses was made (Table 2).

There is a Smart Bike control system's data analysis algorithm in Fig. 4.

Table 2. List of the bicycle control system's events

\begin{tabular}{lll}
\hline № & Event & Response \\
\hline 1 & Cyclist's pulse $>$ OTP & $\begin{array}{l}\text { Display of overcoming the training threshold, offer to turn on the } \\
\text { electric drive }\end{array}$ \\
2 & $\begin{array}{l}\text { Road gradient }>15^{\circ} \text { (uphill) } \\
\text { Display of the warning of an uphill, offer to turn on the electric drive } \\
\text { Display of excessive overcoming the training threshold, offer to stop } \\
\text { for the rest or to continue motion completely on electric drive } \\
\text { Display of the warning of a downhill, electric drive's switching-off, } \\
\text { accumulator charging }\end{array}$ \\
$\begin{array}{lll}\text { Risplay of the need to have a rest, offer to stop for the rest or to turn } \\
\text { on the electric drive }\end{array}$ \\
$\begin{array}{l}\text { Road gradient }<-15^{\circ} \text { (downhill) } \\
6\end{array}$ & Non-stop travelling during more than 2 hours & $\begin{array}{l}\text { Display of excessive overcoming the training threshold, offer to stop } \\
\text { for the rest or to continue motion completely on electric drive } \\
\text { Display of the offer to turn on the electric drive }\end{array}$ \\
\hline
\end{tabular}

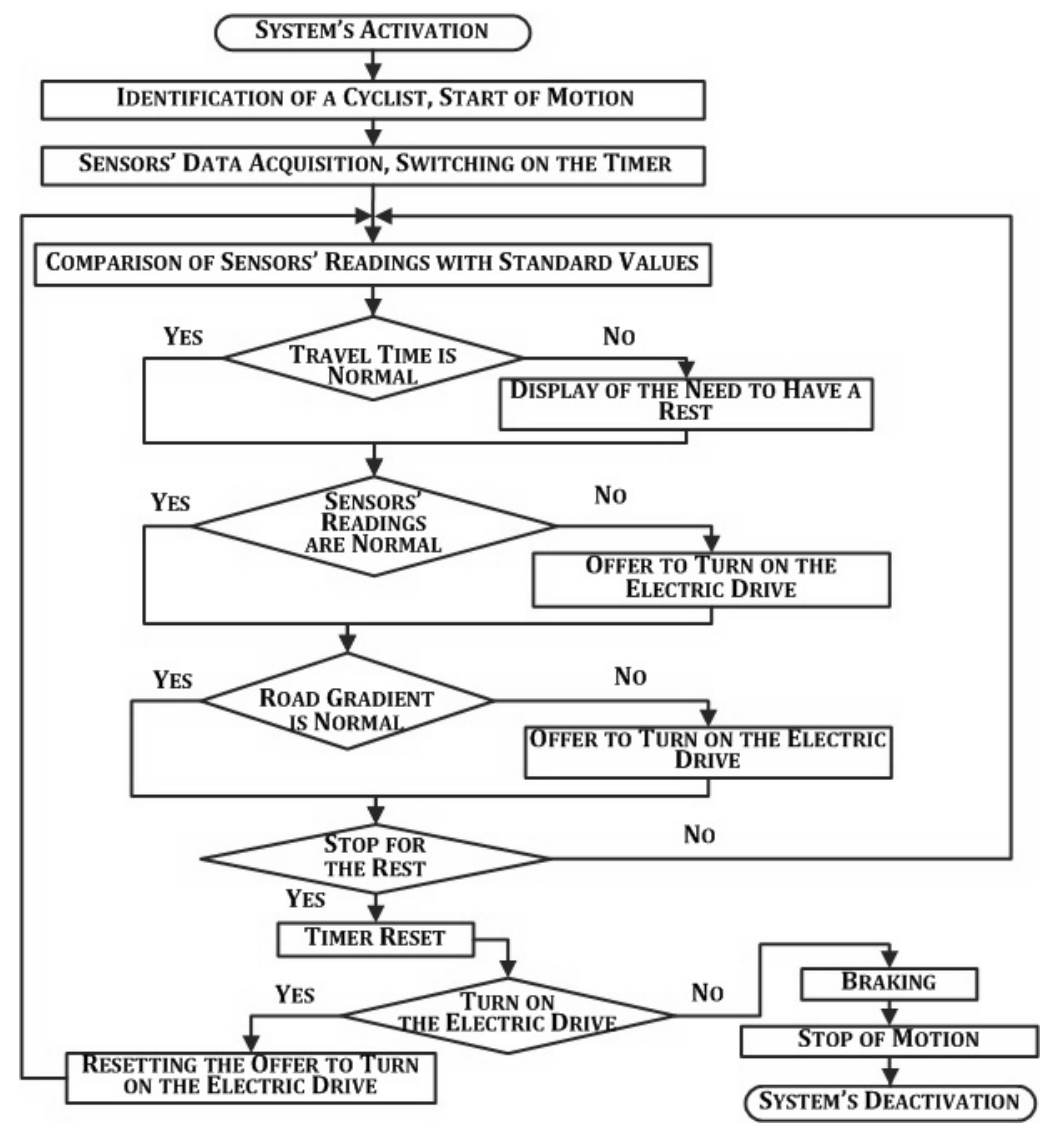

Figure 4. Data analysis algorithm 
Table 3 shows one of the system's operation scripts. If cyclist's pulse value is higher than OTP and the movement speed is less than average speed that is usual for this person, the screen displays an offer to turn on the electric drive. When the pulse value and the speed become normal, the electric drive switches off.

To determine the cyclist's optimal heart rate the formula (1) may be used:

$$
\mathrm{OTP}=(220-\mathrm{A}-\mathrm{PRC}) \cdot \mathrm{K}+\mathrm{PRC},
$$

where OTP - optimal training pulse;

$\mathrm{PRC}$ - pulse in the rest condition;

A - cyclist's age;

$\mathrm{K}$ - coefficient which varies depending on the cyclist's preparation level: $\mathrm{K}=0.6$ for the freshman, $\mathrm{K}=0.65$ for a man of medium-level training, $\mathrm{K}=0.7$ for well-trained person.

Thus, the developed system analyses sensors' readings and if the cyclist, bicycle and the environment parameters' values are not normal, it warns the cyclist about the critical case, as well as offers problems' solutions.

Implementation of the system and test results Conceptual scheme of interaction between modules of the developed system is shown in Fig. 5.
Primary data collection is realized using MPU6050 digital sensors and Pulse Sensor (plug-and-play heart-rate sensor for Arduino). These sensors being located on the steering wheel, on the frame and wheels, as well as on cyclist, are connected to the Arduino board via the $\mathrm{I} 2 \mathrm{C}$ protocol. The motor-wheel MXUS XF39-30H is controlled by Arduino board. Connection to the smartphone is realized via the Bluetooth wireless connection. Sensors' readings are transmitted to the smartphone and then they come into the Microsoft SQL Server database for storage and processing.

The application for smartphones, which was developed with the help of Android Studio in Java, allows to manage the sensor system according to the above-described algorithm and taking into account the state of the external environment as well as the cyclist itself.

The prototype of the developed system was tested in laboratory conditions. The results of tests confirmed that even physically weak category of people can use a bike equipped with the developed system as a mode of transport. Moreover, the widespread introduction of bicycles with such system allows to improve the road safety by avoiding accidents, which are related to fatigue or to a sharp deterioration of cyclists' physical appearance.

An example of the control realization scheme is shown in Fig. 6.

Table 3. An example of the script «Turn on the Electric Drive»

\begin{tabular}{lll}
\hline Step & Event & Action \\
\hline & & $\begin{array}{l}\text { User's condition data collecting (pulse, weight, height, location } \\
\text { tracking, etc.) }\end{array}$ \\
& $\begin{array}{l}\text { The value of the pulse exceeded OTP, } \\
\text { movement speed is less than } 15 \mathrm{~km} / \mathrm{h}\end{array}$ & $\begin{array}{l}\text { Comparison of these indicators with the "reference" values for a } \\
\text { particular cyclist. Display of overcoming the training threshold. Offer to } \\
\text { turn on the electric drive. }\end{array}$ \\
& $\begin{array}{l}\text { Electric drive's switching-off, resetting the display of overcoming the } \\
\text { training threshold }\end{array}$ \\
\hline
\end{tabular}

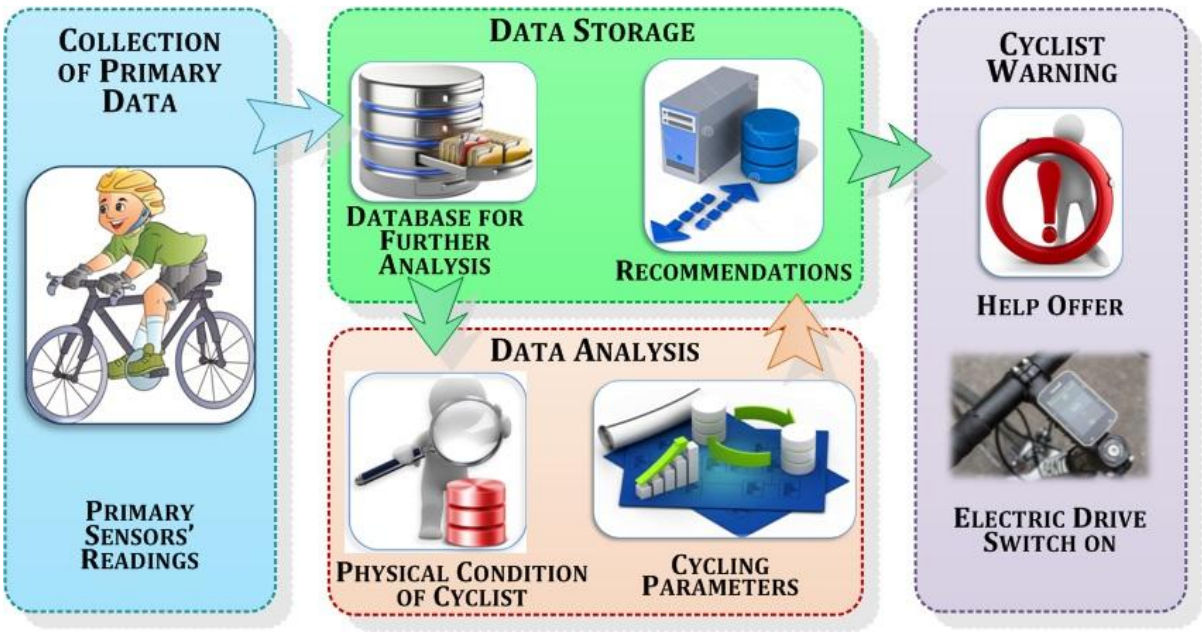

Figure 5. Conceptual model of interaction between system's modules 


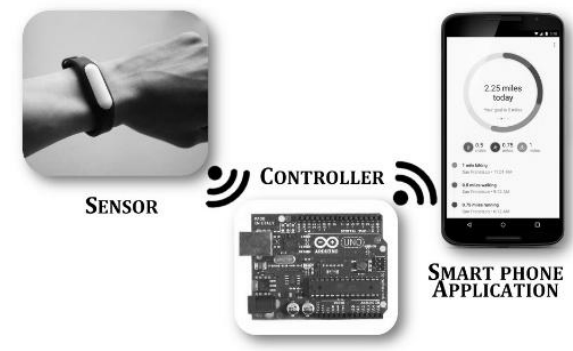

Figure 6. Control realization scheme

\section{The Uniqueness of Our Smart Bike}

Because of the wheel is build in the bicycle's front fork, it is still possible to use this system for multi-speed bicycles. High power offers to go up the hill keeping the same movement speed as well as to use such a system if the cyclist is carrying heavy cargo. Since the system monitors user's physical condition, the battery consumption is considerably reduced. The help by turning on the motor operates only in the case of cyclist fatigue. This allows increasing the maximum distance that untrained person can cycle with this system.

The principal difference between our Smart Bike and Copenhagen Wheel (Tab. 4) [30]:

- A bicycle equipped with a Copenhagen Wheel in effect becomes a pedelec, i.e. a bicycle in which the electric motor assists the rider when necessary but only when they are actively pedalling.

- In our Smart Bike engine helps the driver only in critical conditions.

\subsection{Software solution for the choice of the optimal route}

We offer a software solution for the choice of the optimal route. Route rating should be made from the standpoint of safety, convenience and comfort of passage. To compare the routes the multi-criteria evaluation that considers particular qualities of cyclist and his preferences is used.

The user can set the start and finish points, evaluation criteria and preferences. For the calculation it is also necessary to know such cyclist's parameters as age of cyclist, height, weight and level of physical abilities. Possible routes are evaluated on the base of this information. To do this a matrix of the given route options is constructed and then the overall routes' performance indicators are calculated. The value of the route safety indicator is calculated with provision for correction factors that depend on the physical condition and characteristics of the cyclist. The user receives information about the best possible option. The total length of the route serves to bring the settings (Fig. 7). To implement the proposed idea an application for smartphones integrated with GIS system was developed (Fig. 8). To verify a route the user enters or indicates on the map his location and the destination point. Table 4. Comparison of the Copenhagen Wheel and
Our Smart Bike

\begin{tabular}{|c|c|c|c|c|c|c|}
\hline & 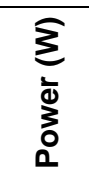 & 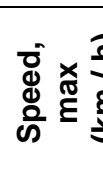 & 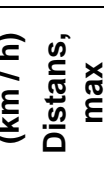 & 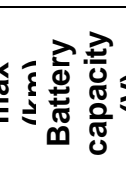 & 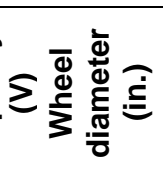 & 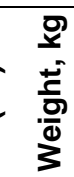 \\
\hline $\begin{array}{l}\text { Copenhagen } \\
\text { Wheel }\end{array}$ & 350 & 32 & 50 & 48 & 26 & 6 \\
\hline Our Smart Bike & 1000 & 50 & - & 48 & 26 & 6,5 \\
\hline
\end{tabular}

The command "find a path" displays a list of routes, sorted by the travel time. After that user can proceed to the route's safety checking. After checking and calculating the overall safety performance indicators, the user can perform the route preview. When scaling up or selecting the particular area on the route map, routes are highlighted in different colours: the dangerous areas are marked in red and yellow. These are such areas as non-signalized pedestrian crossings, lack of bike lanes, etc. Safe areas are marked in green. Thus, the colour of the route depends on the total points of safety, from the green (that is the safest) to red (that is the most dangerous).

The application provides the ability to assess the route by the user. He can leave a feedback and indicate problems on the route by attaching photos or text description. Such feedbacks will help to respond quickly to problems. City authorities and road services, getting information on the state of the infrastructure, may take appropriate action to solve the identified problems.

The application has been tested on the site of the road network of Naberezhnye Chelny city. For the correct work of the application it is necessary to administrate database with actual information (such as the state and characteristics of the road network, infrastructure parameters, etc.) that should be updated when changes occur.

Using the mobile application to find the safest route will not only plan the trip, but also will reduce the possibility of accidents.

Besides, such an application would be useful for the bicycle infrastructure development as it will help to assess how the appearance of new attraction points influence to the cyclists' travel demand and which of the routes are need to be improved. Moreover, data analysis on the accidents with cyclists will help to identify problem areas and inform cyclists about the need of increased attention to unsafe areas when they are planning trips.

Implementation of the intelligent active cyclist assistance systems, the design of correct and safe bicycle paths, their timely maintenance and repair will help to reduce accidents with cyclists.

However, even when implementing intelligent system for the choice of the optimal route it is not always possible to avoid hilly terrain. Bike-lifts and electric drives creation can solve the problem of overcoming steep climbs. In contrast to the electric scooter or motorcycle, e-bike may be driven by pedals. At this time, electric drive is off and accumulator is charging. 


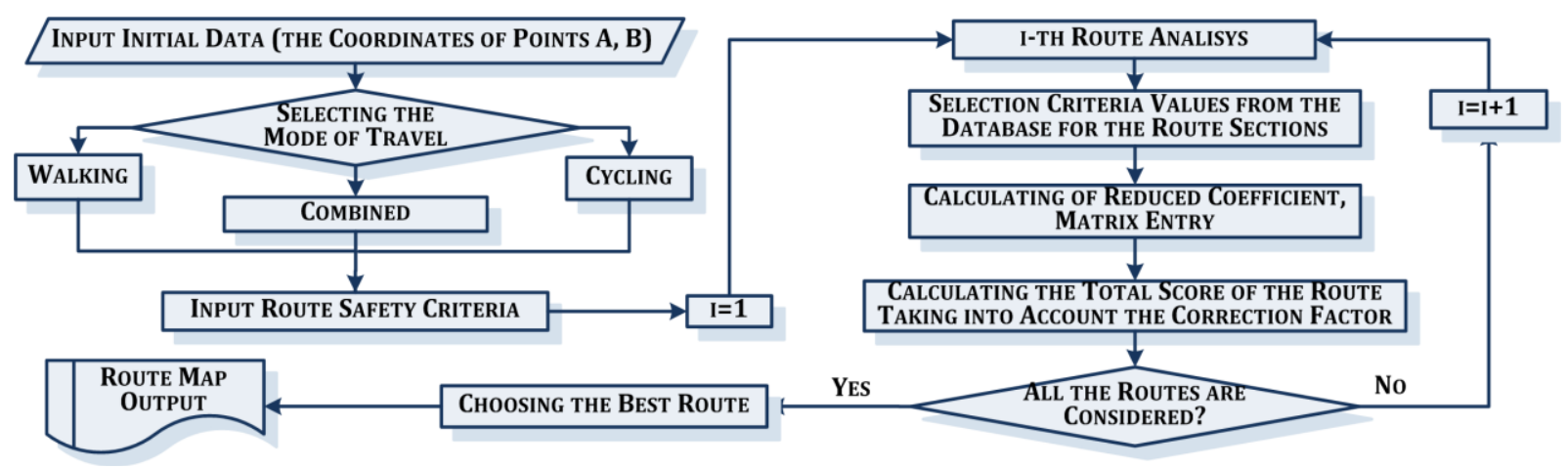

Figure 7. Algorithm for the choice of the optimal route according to safety criteria

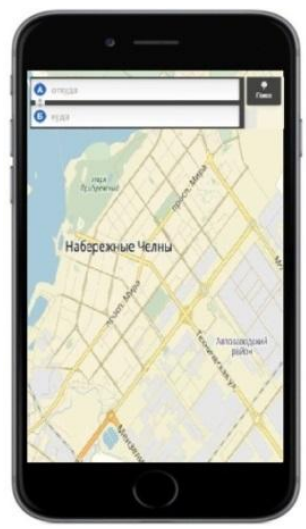

a)

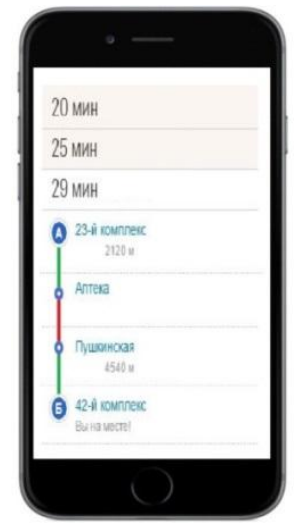

b)

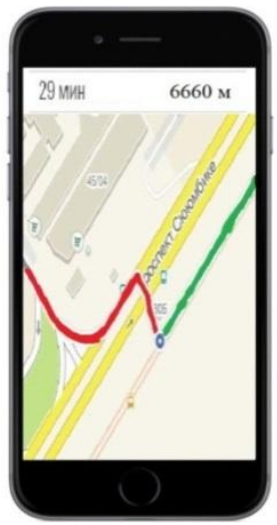

c)

Figure 8. a) selecting the destination point; b) route options; c) route previewing

Smart Bikes with adaptive electric drive that is turns on when it is necessary, can help even physically untrained people to overcome steep climbs and long distances without overload. Accumulator charges from the household electric system. Bicycles provide comparable speeds in urban environments and at the same time energy and economic costs of the one person relocation by bicycle are much more lower than by any other mode of transport, including public transport.

\section{Conclusions}

Despite the obvious advantages of using bicycles for short distances there are still a lot of obstacles to the widespread use of the bicycles as an alternative travel mode. Some of these problems can be solved by two ways: choosing the most secure cycle route's option in developing bicycle infrastructure and creating Smart Bike with adaptive electric drive that is turns on when it is necessary. This cannot be realized without cycling intellectualization. We propose the concept of an information system for bicycle infrastructure planning and modeling and the concept of the Smart Bike control system developed to help the cyclist in situations when the values of his physical condition as well as parameters of environment are critical. To control the cyclist's condition in real time is proposed to use a set of sensors, information transmitting means and the data processing program.

Successful development of Smart City need complex solutions. Implementation of the intelligent active cyclist assistance system, the software solution for the bicycle infrastructure planning, the Smart Bike control system, development of bicycles infrastructure and its integration into the public transport system will contribute to use of bicycle and public transport, as well as will help to increase the road safety, especially for the cyclists. This will create for citizens a comfortable urban environment, as well as obtain a synergistic effect that will contribute to the sustainable development of Smart City. Moreover, the experience of developed countries shows that this clean and efficient kind of transportation also contributes to the economy's development. Besides, the health and longevity also benefits from cycling. As it is seen in Denmark, the cycling benefits are seven times greater than the cost of accidents, in money value the total health impact is worth 230 million Euro.

\section{References}

[1] GREEN CAPACITY, http://greencapacity.ru/ru/ information/smart-cities

[2] Smart cities Preliminary Report 2014, http://www.iso.org/iso/smart_cities_report-jtc1.pdf 
[3] Global status report on road safety 2015, http://www.who.int/violence_injury_prevention/road_sa fety_status/2015/GSRRS2015_Summary_EN_final.pdf

[4] Share the Road: Investment in Walking and Cycling Road Infrastructure, http://www.unep.org/Transport/ sharetheroad/PDF/str_GlobalReport2010.pdf

[5] Global "green" new deal. Policy Brief, http://www.unep.org/pdf/GGND_Final_Report.pdf

[6] Makarova, I., Shubenkova, K., Mavrin, V. et al. (2017): Ways to increase sustainibility of the transportation system. Journal of Applied Engineering Science 15(1): 89-98.

[7] United Nations Human Settlements Programme (UN-HABITAT) (2013) Planning and design for sustainable urban mobility: global report on human settlements (Stoodleigh: Florence Production Ltd.), http://unhabitat.org/books/planning-and-design-forsustainable-urban-mobility-global-report-on-humansettlements-2013/

[8] Medeiros, R. and Duarte, F. (2014) Policy to promote bicycle use or bicycle to promote politicians? Bicycles in the imagery of urban mobility in Brazil. Urban, Planning and Transport Research: An Open Access Journal, 1(1): 28-39.

[9] Tsenkova, S. and Mahalek, D. (2014) The impact of planning policies on bicycle-transit integration in Calgary. Urban, Planning and Transport Research: An Open Access Journal 2: 126-146.

[10] ApPenZeller, M. (2014) Cycling - Past, Present and Future. In RoETHIG, M., EFIMENKo, D. [ed.], Changing urban traffic and the role of bicycles: Russian and International Experiences. (Moscow: Friedrich-EbertStiftung), 11-18.

[11] Cities Developing The World's Best Sustainable Transport Systems, http://www.fastcoexist. com/3025399/4-cities-developing-the-worlds-bestsustainable-transport-systems

[12] Zhang, L., Zhang, J., DuAn, Z., et al. (2015) Sustainable bike-sharing systems: characteristics and commonalities across cases in urban China. Journal of Cleaner Production 97: 124-133.

[13] Nkurunziza, A., Zuidgeest, M., MaARseveen, M.V. (2012) Identifying potential cycling market segments in Dar-es-Salaam, Tanzania. Habitat Int. 36: 78-84.

[14] Hidalgo, D. and Huizenga, C. (2013) Implementation of sustainable urban transport in Latin America. Research in Transportation Economics 40: 66-77.

[15] Medeiros, R. and Duarte, F. (2014) Policy to promote bicycle use or bicycle to promote politicians? Bicycles in the imagery of urban mobility in Brazil. Urban, Planning and Transport Research: An Open Access Journal, 1(1): 28-39.

[16] Bredal, F. (2014) The Case of Copenhagen. In Roethig, M., EFIMENKo, D. [ed.], Changing urban traffic and the role of bicycles: Russian and International Experiences. (Moscow: Friedrich-EbertStiftung), 24-28.

[17] LENZ, B. and RiEHLE, E. (2013) Bikes for urban freight? Experience in Europe. Transp. Res. Rec.: J. Transp. Res. Board, 39-45.

[18] Wrighton, S. (2012) D3.6 Campaign Scheme Shopby-Bike. CycleLogistics - Moving Europe Forward, http://one.cyclelogistics.eu/docs/114/D3_6_Campaign _Scheme_Shop_By_Bike_08042014_final.pdf

[19] Smart City, http://city-smart.ru/info/125.html
[20] Arsenio, E., Martens, K. and Di Ciommo, F. (2016) Sustainable urban mobility plans: Bridging climate change and equity targets? Research in Transportation Economics 55: 30-39.

[21] Mityaev, A. (2014) The Case of Moscow. In RoethiG, M., EFIMENKo, D. [ed.], Changing urban traffic and the role of bicycles: Russian and Int. Experiences. (Moscow: Friedrich-Ebert-Stiftung), 72-79.

[22] HANDY, S. and XING, Y. (2011) Factors correlated with bicycle commuting: A study in six small US cities. International Journal of Sustainable Transportation $\mathbf{5}$ : 91-110.

[23] Verma, M., Rahul, T., Reddy, P. et al. (2016) The factors influencing bicycling in the Bangalore city. Transportation Research, Part A, 89: 29-40.

[24] Heinen, E., WeE, B. and MaAt, K. (2010) Commuting by Bicycle: An Overview of the Literature. Transport Reviews 30: 59-96.

[25] Tahrola, P. (2014) The Case of Oulu. In Roethig, M., EFIMENKO, D. [ed.], Changing urban traffic and the role of bicycles: Russian and Int. Experiences. (Moscow: Friedrich-Ebert-Stiftung), 29-43.

[26] Makarova, I., Shubenkova, K. and Gabsalikhova, L. (2017) Analysis of the city transport system's development strategy design principles with account of risks and specific features of spatial development. Transport Problems 12(1): 125-138.

[27] Makarova, I., Shubenkova, K., Pashkevich, A. et al. (2017) Smart-bike as one of the ways to ensure sustainable mobility in smart cities. Lecture Notes of the Institute for Computer Sciences, Social-Informatics and Telecommunications Engineering, LNICST 205:187198.

[28] Bicycle innovation lab, http://www.bicycleinno vationlab.dk/activities/data-popular-bikes?show=lgg

[29] Makarova, I., Khabibullin R., Shubenkova, K. et al. (2016) Ensuring sustainability of the city transportation system: Problems and solutions (ICSC). E3S Web of Conferences 6: 02004.

[30] Makarova, I., Shubenkova, K., Mavrin, V. et al. (2017) Development of sustainable transport in smart cities. In Proceedings of $3 r d$ IEEE Int. Forum on Research and Technologies for Society and Industry, RTSI 2017, Modena, Italy, September 2017, http://ieeexplore.ieee.org/stamp/stamp.jsp?arnumber= 8065922 